\title{
Sensitivity Analysis and Parameter Estimation of Heat Transfer and Material Flow Models in Friction Stir Welding
}

\author{
S. Pereyra*, G.A. Lombera, G. Frontini, S.A. Urquiza \\ Universidad Nacional de Mar del Plata, Mar del Plata (7600), Argentina
}

Received: May 14, 2013; Revised: August 26, 2013

\begin{abstract}
Although numerical models of heat transfer and material flow have contributed to understand the underlying mechanisms of friction stir welding (FSW), there are certain input model parameters that can not be easily determined. Thus, the model predictions do not always agree with experimental results. In this work, sensitivity analysis and parameter estimation were applied to test heat transfer and material flow models. A forward-difference approximation was used to compute the sensitivity of the solution with respect to the unknown model parameters. The Levenberg-Marquardt (LM) method was applied to solve the nonlinear parameter estimation problem. The numerical models were developed by the finite element method (FEM). The way in which the unknown model parameters independently affect the results and the importance of the location of reference points that take part in the objective function were determined.
\end{abstract}

Keywords: friction stir welding, sensitivity analysis, parameter estimation, finite element method, CFD

\section{Introduction}

Friction stir welding is a solid state welding process, i.e. the joint occurs below the material melting point ${ }^{1-3}$. The tool consists of a shoulder and a pin. Basically the process involves plunging the pin of the rotating tool into the weld line until the shoulder contacts the surface of the workpieces and then moving the tool along the welding line. The tool leads the material from the front to the back of the pin stirring the metal in the solid state. This region is called the stir zone. A backing plate rigidly fixes the workpieces and also participates in the extraction of heat from the workpieces.

There is the need to determine how the variations of the processing variables (welding and rotational speed, plunge force, tool design, etc.) affect the final properties of the weld. In this sense there are some studies carried out in the experimental ${ }^{1}$ and numerical modeling ${ }^{4}$ fields.

Several different approaches have been applied to modeling the FSW process, ranging from simple analytical thermal models based on Rosenthal's solutions ${ }^{5,6}$ to three-dimensional thermo-mechanical models. Thermomechanical modeling of FSW generally falls into two categories: Eulerian models $\mathrm{s}^{7-9}$ and Lagrangian models $\mathrm{s}^{10-12}$. The use of an Eulerian reference frame is advantageous in analyzing the steady-state of the process concerning computational efficiency, avoiding mesh distortion. The arbitrary Lagrangian-Eulerian description is suitable for tracking the material free surface in contact with a threaded tool pin $^{13-15}$.

Heat transfer and material flow models applied to the FSW process have contributed to understanding the FSW welding process. However, there are certain input model

*e-mail: pereyra.sebastian@gmail.com parameters whose values can not be easily determined ${ }^{2}$. Thus, numerical models together with parameter estimation techniques are essential for providing reliable results.

There are studies where the parameter estimation technique has been applied to the modeling of welding processes. In fusion welding process, De and DebRoy ${ }^{16}$ used heat transfer and fluid flow models estimating values of several uncertain input parameters using experimental data. In FSW process, Zhu and $\mathrm{Chao}^{17}$ carried out a heat transfer model in which the moving heat source and the contact resistance were obtained performing inverse analysis. Also, Nandan et al. ${ }^{18}$ and Pereyra et al..$^{19}$ applied estimatio $n$ parameters techniques to heat and material flow models during friction stir welding. Moreover, Assidi et al. ${ }^{20}$ applied inverse analysis approach to find the coefficient values of different friction models by fitting numerical results with measured welding forces and temperatures. Recently, Larsen et al. ${ }^{21}$ determined the magnitude and spatial distribution of the heat transfer coefficient or thermal conductance toward the backing plate by minimizing the difference between experimental measurements of temperature and temperatures obtained using a three dimensional finite element model.

The aim of this work is to determine which model parameters affect more significantly the models' steady state temperature results and to establish where is more convenient to locate the reference temperatures in order to avoid drawbacks in the estimation procedure.

The thermo-mechanical model and the complementary models were solved by the $\mathrm{FEM}^{22}$ for the computation of reference temperatures and sensitivity coefficients, and to perform the parameter estimation procedure ${ }^{23}$. 


\section{Mathematical Models}

The experimental setup (Figure 1) is represented by a geometric model which consists of a tool (cylindrical unthreaded pin), workpieces (two 304 L stainless steel plates) and a backing plate.

The geometry dimensions of the model are referred to in Table 1 and correspond to the data of the work of Zhu and $\mathrm{Chao}^{17}$.

\subsection{Thermomechanical coupled model}

The momentum conservation equations in an Eulerian description, considering a coordinate system attached to the tool axis, are:

$\operatorname{div}(\boldsymbol{\sigma})+\rho \cdot g=\rho \cdot \frac{d \boldsymbol{u}}{d t}$

where $\sigma$ is the Cauchy stress tensor, $u$ is the velocity vector of plastic flow, $\rho$ is the density, $g$ is the acceleration of gravity and $t$ is the time.

According to the assumed flow formulation the Cauchy stress tensor is:

$$
\begin{aligned}
& \boldsymbol{\sigma}=-p \cdot \boldsymbol{\delta}+\tau \\
& \tau=2 \cdot \mu \cdot \boldsymbol{d} \\
& \boldsymbol{d}=\frac{1}{2} \cdot\left(\nabla \boldsymbol{u}+\nabla \boldsymbol{u}^{\mathrm{T}}\right)
\end{aligned}
$$
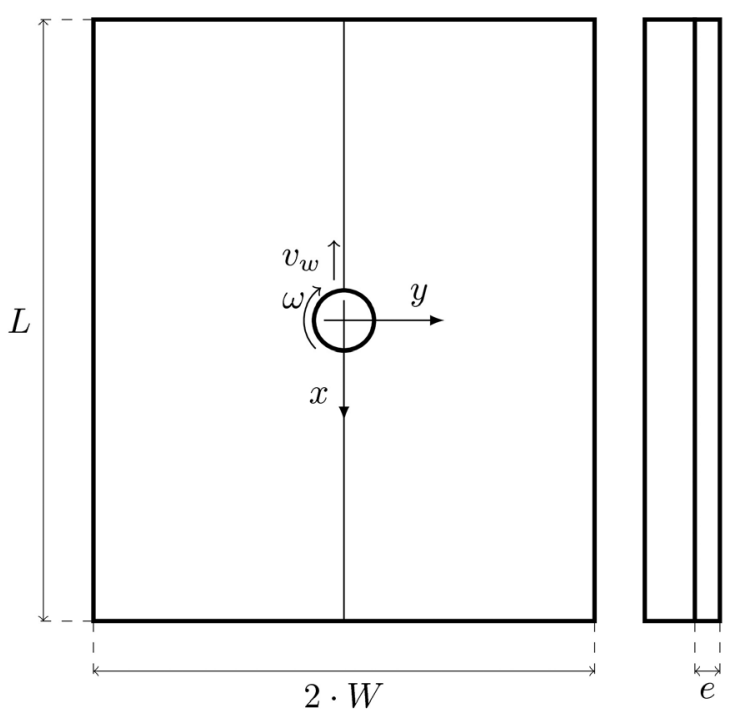

Figure 1. Experimental setup and dimensions.

Table 1. Model geometry dimensions.

\begin{tabular}{lc}
\hline \multicolumn{1}{c}{ Workpieces } & Size \\
\hline length $(L)$ & $304.8 \mathrm{~mm}$ \\
width $(W)$ & $101.6 \mathrm{~mm}$ \\
thickness $(e)$ & $3.18 \mathrm{~mm}$ \\
\hline \multicolumn{1}{c}{ Tool } & Size \\
\hline pin diameter $\left(D_{\mathrm{p}}\right)$ & $6.35 \mathrm{~mm}$ \\
shoulder diameter $\left(D_{\mathrm{s}}\right)$ & $19.05 \mathrm{~mm}$ \\
\hline
\end{tabular}

where $p$ is the pressure, $\delta$ is the Kronecker's delta, $\tau$ is the stress deviator tensor, $\mu$ is the viscosity and $d$ is the strain rate tensor.

Assuming a rigid visco-plastic material model, the viscosity is defined as:

$$
\mu=\frac{\sigma_{\mathrm{f}}}{3 \cdot \dot{\varepsilon}_{e}}
$$

where $\sigma_{\mathrm{f}}$ is the flow stress and $\dot{\varepsilon}_{e}$ is the effective strain rate (the second invariant of the strain rate tensor) defined as follows:

$\dot{\varepsilon}_{e}=\sqrt[2]{\frac{2}{3} \cdot \boldsymbol{d}: \boldsymbol{d}}$

The material is assumed to be rigid visco-plastic. The flow stress ${ }^{24}$ is as follows:

$$
\sigma_{\mathrm{f}}=\frac{1}{\alpha} \cdot \sinh ^{-1}\left[\left(\frac{Z}{A}\right)^{\frac{1}{n_{c}}}\right]
$$

where $A, \alpha$ and $n_{c}$ are material constants and $Z$ is the ZenerHollomon parameter:

$$
Z=\dot{\varepsilon}_{e} \cdot \exp \left(\frac{Q}{R \cdot T}\right)
$$

where $T$ is the temperature, $Q$ is the activation energy and $R$ is the universal gas constant.

The continuity equation for incompressible flow is:

$\operatorname{div}(\boldsymbol{u})=0$

The heat conservation equation is:

$\rho \cdot C_{p} \cdot \frac{d T}{d t}=\operatorname{div}(K \cdot \nabla \mathrm{T})+\rho \cdot \gamma$

where $C_{p}$ is the specific heat, $K$ is the thermal conductivity and $\gamma$ is a source term, the heat generation rate per unit mass due to plastic deformation:

$\gamma=\eta \cdot \tau: d$

where $\eta$ is the mechanical efficiency, i.e. the amount of mechanical energy converted to heat energy.

\subsection{Complementary models}

The heat flux of the workpieces and tool surfaces exposed to the environment involved convective and radiative heat transfer described by

$$
q=h \cdot\left(T-T_{0}\right)+\varepsilon \cdot \sigma_{\mathrm{SB}} \cdot\left(T^{4}-T_{0}^{4}\right)
$$

where $h$ is the convective heat transfer coefficient, $T_{0}$ is the ambient temperature, $\varepsilon$ is the surface emissivity coefficient and $\sigma_{\mathrm{SB}}$ is the Stefan-Boltzmann constant.

A relation, extracted from the cross-wedge rolling process $^{8}$, is considered to deal with the extent of slip between all tool-workpieces' interface, as follows:

$$
\delta=1-\exp \left(-\frac{1}{\delta_{0}} \cdot \frac{r}{R_{s}}\right)
$$


where $\delta$ is the fraction-slip, $\delta_{0}$ is the fraction-slip constant, $r$ is the radial distance from the tool axis and $R_{s}$ is the tool shoulder radius. $\delta=0$ indicates full sticking.

The heat flux due to the frictional heating between the tool and the workpieces' surface is:

$q=\mu_{\mathrm{f}} \cdot P_{\mathrm{N}} \cdot \delta \cdot \omega \cdot r$

where $\omega$ is the angular velocity, $P_{\mathrm{N}}$ is the normal pressure and $\mu_{\mathrm{f}}$ is the friction coefficient:

$\mu_{\mathrm{f}}=\mu_{0} \cdot \exp \left(-\lambda_{\mathrm{f}} \cdot \delta \cdot \omega \cdot r\right)$

where $\mu_{0}$ is the friction constant, $\lambda_{\mathrm{f}}$ is a constant for the dimensions.

The heat flux towards the backing plate is given by:

$q=h_{b} \cdot \Delta T$

where $h_{b}$ is the heat transfer coefficient and $\Delta T$ is the temperature difference between the workpieces and backing plate contact surfaces.

Table 2 shows the values of all known parameters involved in the models.

\section{Inverse Analysis}

The models described above involve some parameters that can not be easily determined, this implies the need to perform an inverse analysis. These unknown parameters are:

Table 2. Model known parameters.

\begin{tabular}{|c|c|}
\hline \multicolumn{2}{|c|}{ Plates Prameters } \\
\hline density $(\rho)$ & $8,000 \mathrm{Kg} / \mathrm{m}^{3}$ \\
\hline specific heat $\left(C_{p}\right)$ & $500 \mathrm{~J} / \mathrm{Kg}{ }^{\circ} \mathrm{C}$ \\
\hline thermal conductivity $(K)$ & $21.4 \mathrm{~W} / \mathrm{m}^{\circ} \mathrm{C}$ \\
\hline convective coef. $(h)$ & $10.0 \mathrm{~W} / \mathrm{m}^{2}{ }^{\circ} \mathrm{C}$ \\
\hline emissivity coef. $(\varepsilon)$ & 0.17 \\
\hline Stefan-Boltzman c. $(\sigma)$ & $5.76 \times 10 \mathrm{~W} / \mathrm{m}^{2}{ }^{\circ} \mathrm{C}^{4}$ \\
\hline material constant $(A)^{25}$ & $8.30 \times 10^{15}$ \\
\hline material constant $(\alpha)^{25}$ & $12,000 \mathrm{~Pa}^{-1}$ \\
\hline material constant $\left(n_{c}\right)^{25}$ & 4.32 \\
\hline activation energy $(Q)^{25}$ & $21.4 \mathrm{~J} / \mathrm{mol}$ \\
\hline univ. gas constant $(R)$ & $8.314 \mathrm{~J} / \mathrm{mol}^{\circ} \mathrm{C}$ \\
\hline \multicolumn{2}{|c|}{ Tool Parameters } \\
\hline density $(\rho)$ & $7,800 \mathrm{Kg} / \mathrm{m}^{3}$ \\
\hline specific heat $\left(C_{p}\right)$ & $500 \mathrm{~J} / \mathrm{Kg}^{\circ} \mathrm{C}$ \\
\hline thermal conductivity $(K)$ & $43.0 \mathrm{~W} / \mathrm{m}^{\circ} \mathrm{C}$ \\
\hline convective coef. $(h)$ & $10.0 \mathrm{~W} / \mathrm{m}^{2}{ }^{\circ} \mathrm{C}$ \\
\hline emissivity coef. $(\varepsilon)$ & 0.8 \\
\hline rotational speed $(\omega)$ & $300 \mathrm{rpm}$ \\
\hline welding speed $\left(v_{w}\right)$ & $1.693 \mathrm{~mm} / \mathrm{seg}$ \\
\hline plunging force $\left(P_{\mathrm{N}}\right)$ & $31,138 \mathrm{~N}$ \\
\hline constant for the $\operatorname{dim} .\left(\lambda_{f}\right)$ & $10^{-3} \mathrm{~cm} / \mathrm{seg}$ \\
\hline \multicolumn{2}{|c|}{ Backing plate parameters } \\
\hline density $(\rho)$ & $7,800 \mathrm{Kg} / \mathrm{m}^{3}$ \\
\hline specifc heat $\left(C_{p}\right)$ & $500 \mathrm{~J} / \mathrm{Kg} \cdot{ }^{\circ} \mathrm{C}$ \\
\hline thermal conductivity $(K)$ & $43.0 \mathrm{~W} / \mathrm{m}^{\circ} \mathrm{C}$ \\
\hline
\end{tabular}

the fraction-slip constant $\left(\delta_{0}\right)$, the mechanical efficiency $(\eta)$, the heat transfer coefficient of the workpieces-backing plate interface $\left(h_{\mathrm{b}}\right)$ and the friction constant $\left(\mu_{0}\right)$.

Figure 2 shows numerical temperature profiles compared to thermocouple temperature measurements on an experimental test at different distances from the welding line at the top and at the bottom of the plates. The numerical results were obtained assigning values found in literature ${ }^{8,17}$ for the unknown parameters $\left(\delta_{0}=0.4\right.$, $\eta=0.5, h_{\mathrm{b}}=400 \mathrm{~W} / \mathrm{m}^{2}{ }^{\circ} \mathrm{C}$ and $\left.\mu_{0}=0.4\right)$ and considering measurements ${ }^{17}$ as reference values.

Figure $3 \mathrm{~b}$ shows temperature distribution at a distance of $1.8 \mathrm{~cm}$ from the welding line for experimental measurements (exp), numerical results with literature suggested values $(n=0)$ and numerical results performing parameter estimation $(n=N)$. In the figure, $n$ is the iteration number, 0 is the initial iteration, and $N$ is the final iteration. These results were obtained performing a parameter estimation procedure considering the four unknown parameters taking as reference 18 points from experimental measurements (Figure 3a). The numerical solution was improved but a sensitivity analysis was found to be necessary to complete the outlook.

Due to the different units and orders of magnitude of these four parameters, it is convenient for the further calculation, to normalize them considering each reference value $\left(\delta_{0}^{0}=0.4, \eta^{0}=0.5, h_{0}^{0}=400 \mathrm{~W} / \mathrm{m}^{2}{ }^{\circ} \mathrm{C}\right.$ and $\left.\mu_{0}^{0}=0.4\right)$ :

$\beta_{1}=\frac{\delta_{0}}{\delta_{0}^{0}}, \beta_{2}=\frac{\eta}{\eta^{0}}, \beta_{3}=\frac{h_{b}}{h_{b}^{0}}$, and $\beta_{4}=\frac{\mu_{0}}{\mu_{0}^{0}}$

\subsection{Sensitivity analysis}

Sensitivity analysis in the surroundings of each reference value was performed for the parameter set to determine which of them are important to consider in the estimation procedure.

Normalized sensitivity field corresponds to the first derivative of the model temperature field with respect of the normalized parameter $\beta_{j}$. A forward-difference approximation is considered to compute the field as follows:

$$
\frac{\partial T}{\partial \beta_{j}}=\frac{T\left(\beta_{1}, \ldots, \beta_{j}+\Delta \beta_{j}, \ldots, \beta_{\mathrm{N}}\right)-T\left(\beta_{1}, \ldots, \beta_{j}, \ldots, \beta_{\mathrm{N}}\right)}{\Delta \beta_{j}}
$$

\subsection{Parameter estimation approach}

The parameter estimation problem is formulated in order to find the model parameters that minimize an objective function defined as:

$$
F(\boldsymbol{\beta})=\sum_{i=1}^{M}\left[f_{i}(\boldsymbol{\beta})\right]^{2}
$$

where $\beta$ is the parameter vector, $M$ is the total number of objective points, and $f_{i}$ are functions given by:

$$
f_{i}(\boldsymbol{\beta})=T_{i}^{O}-T_{i}(\boldsymbol{\beta})
$$

where $T_{i}^{0}$ are the objective temperatures and $T_{i}(\boldsymbol{\beta})$ are the computed temperatures.

The iterative scheme for the normalized parameters obtained by the Levenberg-Marquard method $^{26}$ is: 


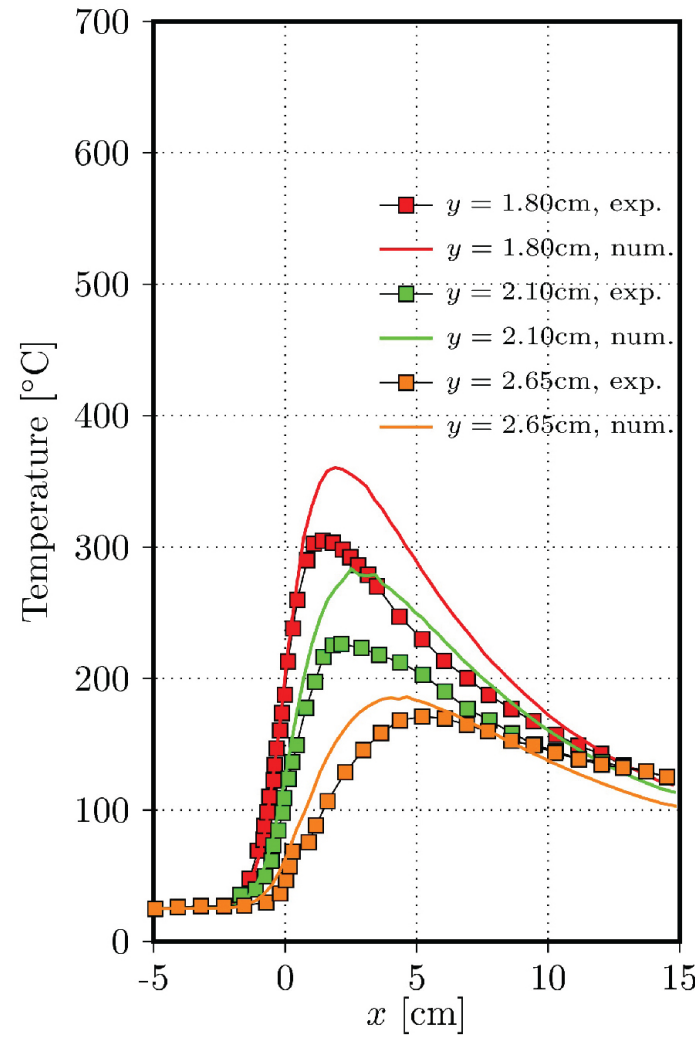

(a)

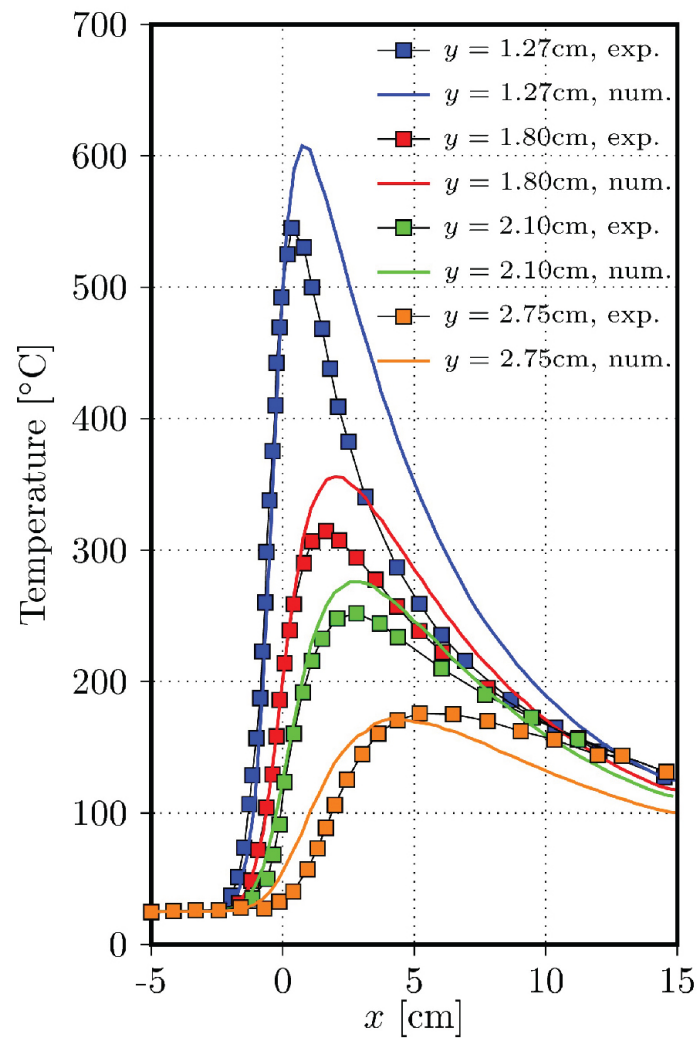

(b)

Figure 2. Numerical (lines) and experimental (points) temperature profiles (a) at the top and (b) at the bottom of the plates.

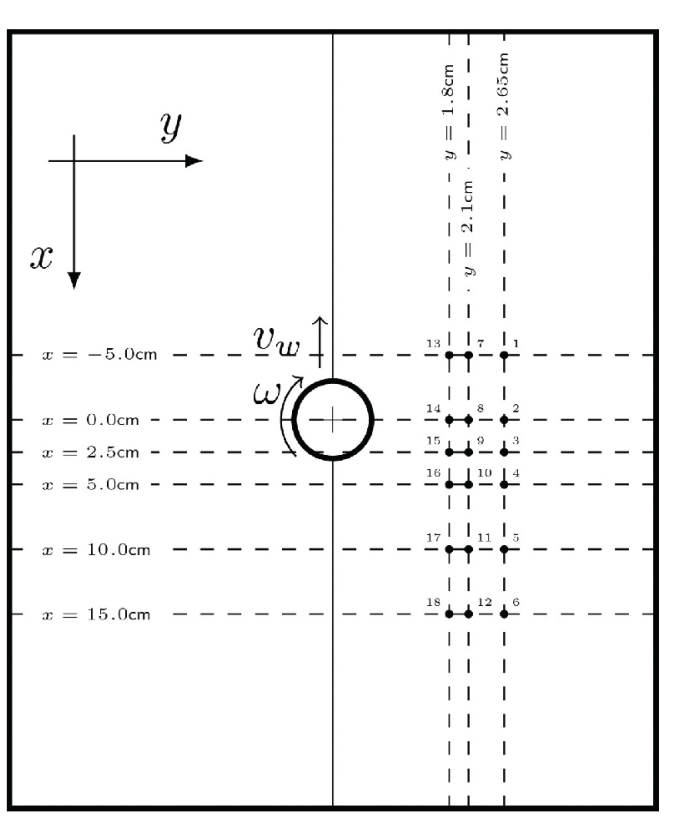

(a)

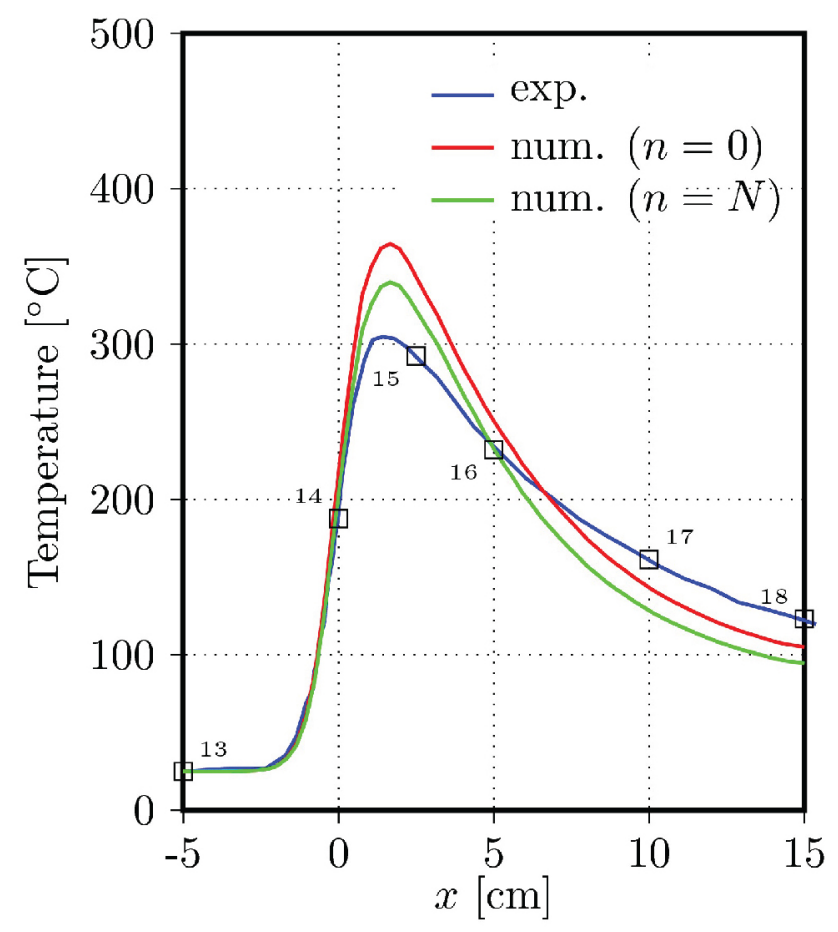

(b)

Figure 3. Parameter estimation procedure: (a) reference points and (b) numerical results. 
$\boldsymbol{\beta}^{n+1}=\boldsymbol{\beta}^{n}+\left(\mathbf{X}^{n \mathrm{~T}} \cdot \mathbf{X}^{n}+\lambda \cdot \mathbf{I}\right)^{-1} \cdot \mathbf{X}^{n \mathrm{~T}} \cdot\left(\mathbf{T}^{0}-\mathbf{T}^{n}\right)$

where the superscripts $n$ and $n+1$ denote the previous and the actual iteration step, respectively, $\mathbf{I}$ is the identity matrix, $\mathbf{X}$ is the sensitivity matrix of component $X_{i j}$, and correspond to the first derivative of the model temperatures for the $i$ th objective point with respect to the normalized parameter $\beta_{j}$, and $\lambda$ is a scalar damping coefficient.

The direct problem (Figure 4) was taken as reference, i.e. the objective temperatures $T_{i}^{0}$ are not really measured but they are computed considering the complete model presented (see Section 2) using the target values of the unknown parameters.

Figure 3 shows the temperature distribution corresponding to three different locations: T1Ref, T2Ref and T3Ref. T1Ref and T3Ref were placed on the top of the plates (workpieces), at a distance of $D_{s}$ and $1.5 \cdot D_{s}$ from the welding center line, respectively. T2Ref was placed in the backing plate at a distance of $0.125 \cdot e$ from the bottom of the plates. The top left corner of the graph exhibits a cross section area, perpendicular to the weld center line of the geometry, indicating the concerned locations.

Two different cases were considered to determine how the objective points locations affect the estimation procedure. Case (a) considers temperature distribution T1Ref and T2Ref, and case (b) T1Ref and T3Ref. The first guesses for the normalized parameters were obtained by incrementing them $20 \%$ of their reference value.

\section{Results and Discussion}

Direct experimental measurement of the temperature field within the stir zone is a difficult task ${ }^{1}$ and such measurements (i.e. reference temperature) are restricted to adjacent places. In addition, out of the stir zone, temperature results do not change in a substantial way between the bottom and the top of the workpieces ${ }^{17}$. For these two reasons, sensitivity field results are shown in the middle plane of the plates and were considered out of the tool shoulder radius.

By comparing the normalized sensitivity field of parameters, in the surroundings of each reference value (Figure 5), some ideas can be extracted. First, on the plates the normalized parameters $\beta_{2}$ and $\beta_{3}$ produced the greater changes in temperature numerical results. On the other hand, the normalized parameter $\beta_{1}$ produced the smaller ones. In the case of the normalized parameters $\beta_{2}$ and $\beta_{3}$, it is observed that the values achieved behind the tool, out of the stir zone, are higher for the latter than for the former.

In the backing plate, the only normalized parameter that results in significant values is $\beta_{3}$. Moreover, for $\beta_{3}$ the sensitivity field on the workpieces have an opposite sign than on the backing plate, i.e. with parameter increment the temperature field decreases on the workpieces and increases on the backing plate.

It can also be noted that the sensitivity field corresponding to $\beta_{2}$ and $\beta_{4}$ may be correlated. This means that both parameters can't be computed from the same estimation procedure. This fact is not surprising because both parameters correspond to local heat generation close to the tool-workpieces interface that increase the temperature field which in turn is affected by the convection due to the material flow.

Considering the concepts extracted from the sensitivity analysis, normalized parameters $\beta_{2}$ and $\beta_{3}$ were taken into account to carry out the estimation procedure.

Figure 6 shows the value the objective function takes at each iteration step, both case (a) and case (b). From this it follows that case (a) achieves the target normalized parameters (Table 3) reaching the global minimum for which

Table 3. Initial and final values of the parameters.

\begin{tabular}{lcc}
\hline & $\boldsymbol{\eta}$ & $\boldsymbol{h}_{\boldsymbol{b}}\left[\mathbf{W} / \mathbf{~ m}^{\mathbf{2}}{ }^{\circ} \mathbf{C}\right]$ \\
\hline initial value & 0.6 & 480 \\
final value - case (a) & 0.5 & 400 \\
final value - case (b) & 0.56 & 436 \\
\hline
\end{tabular}

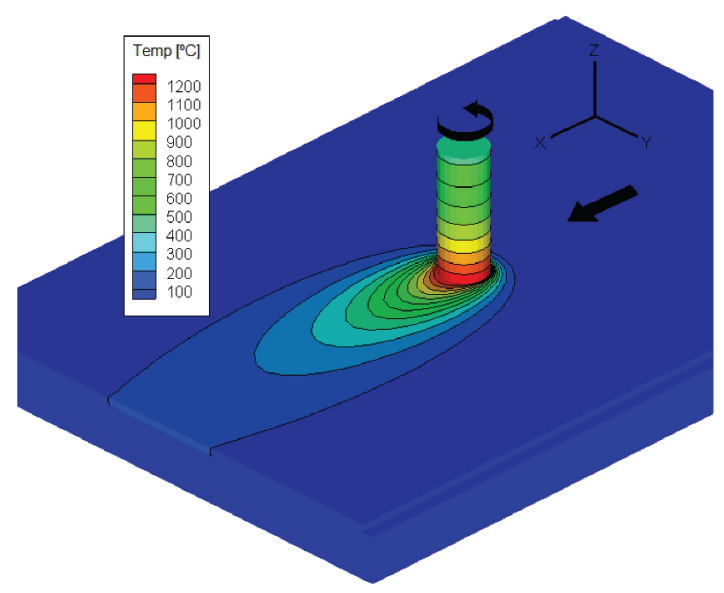

(a)

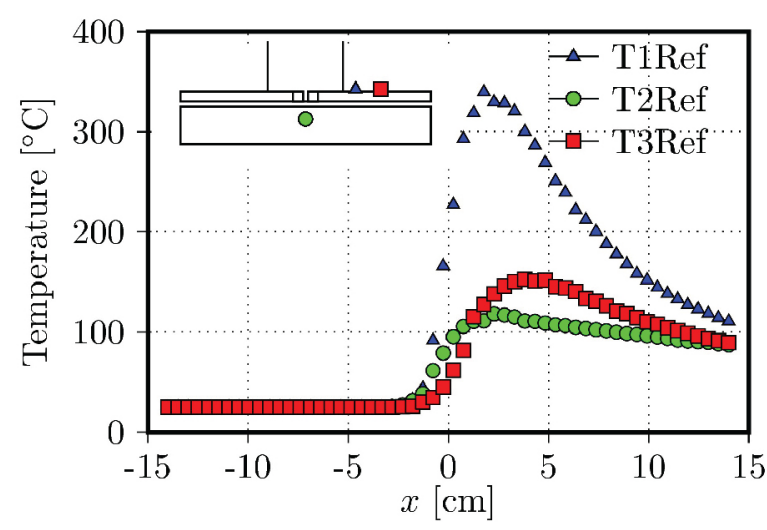

(b)

Figure 4. (a) Temperature field of the direct problem (b) Temperature distributions. 

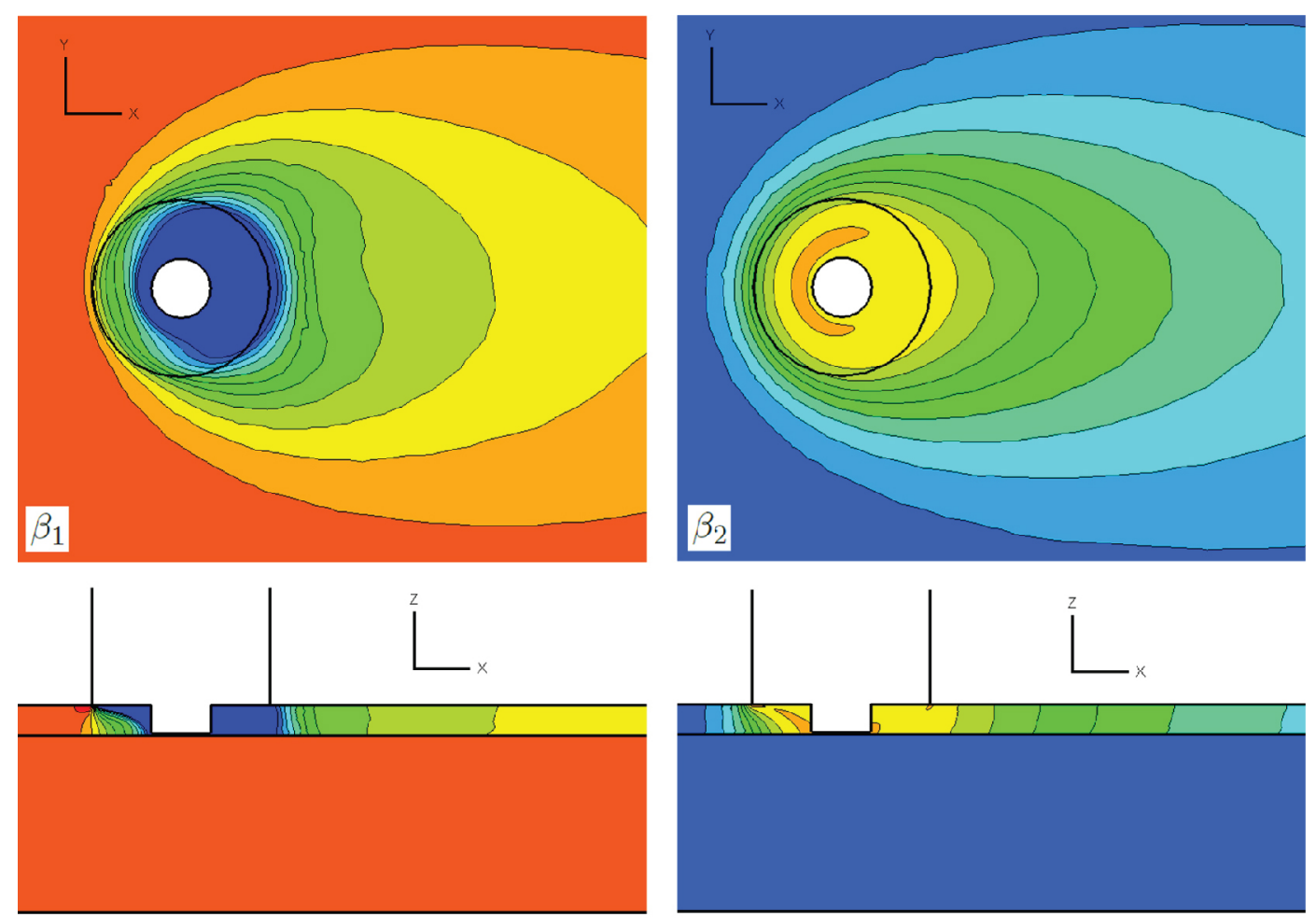

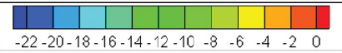

(a)
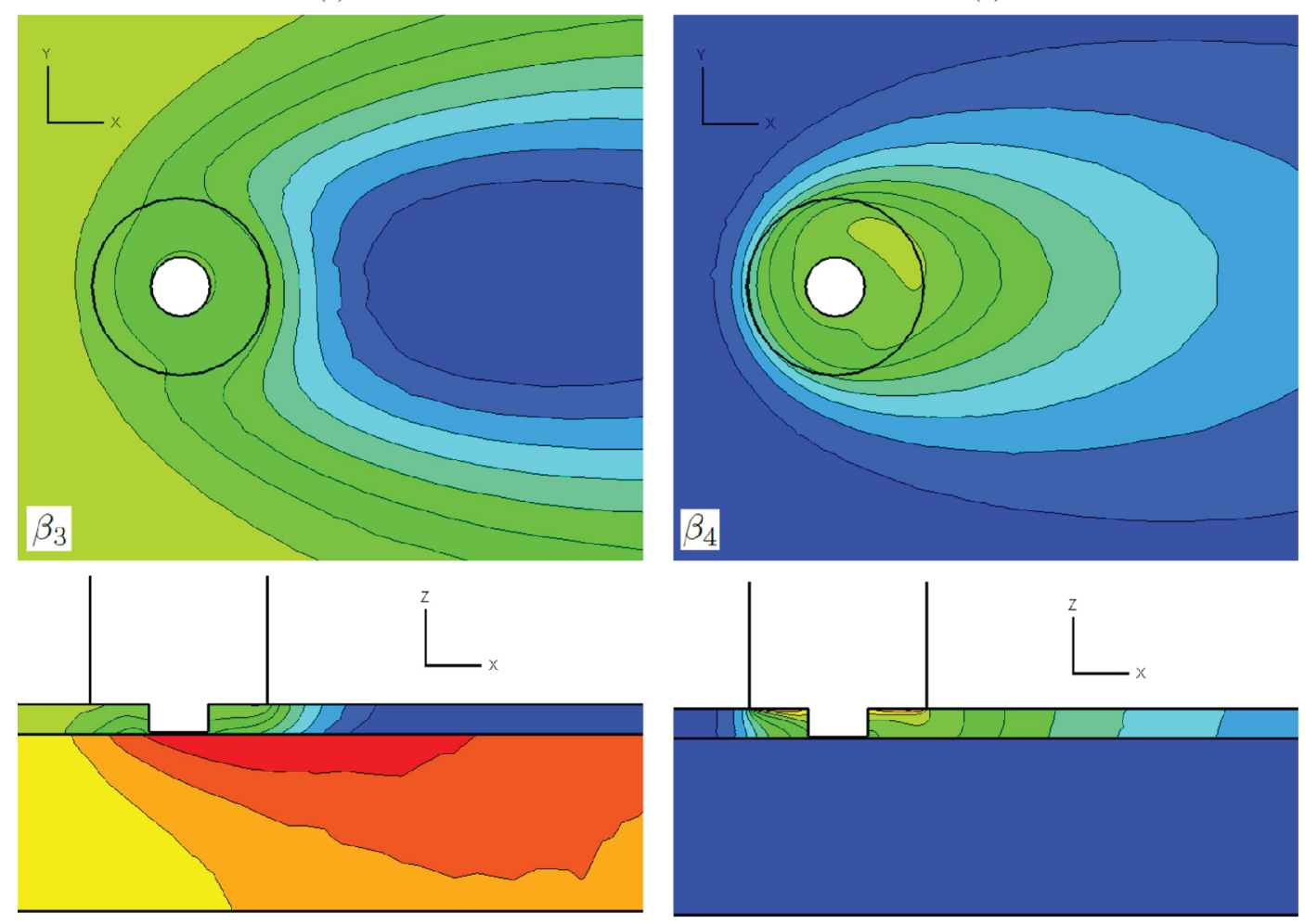

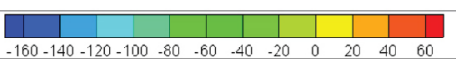

(c)

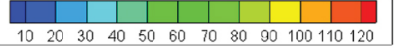

(d)

Figure 5. Sensitivity field for (a) $\beta_{1}$, (b) $\beta_{2}$, (c) $\beta_{3}$ and (d) $\beta_{4}$. 


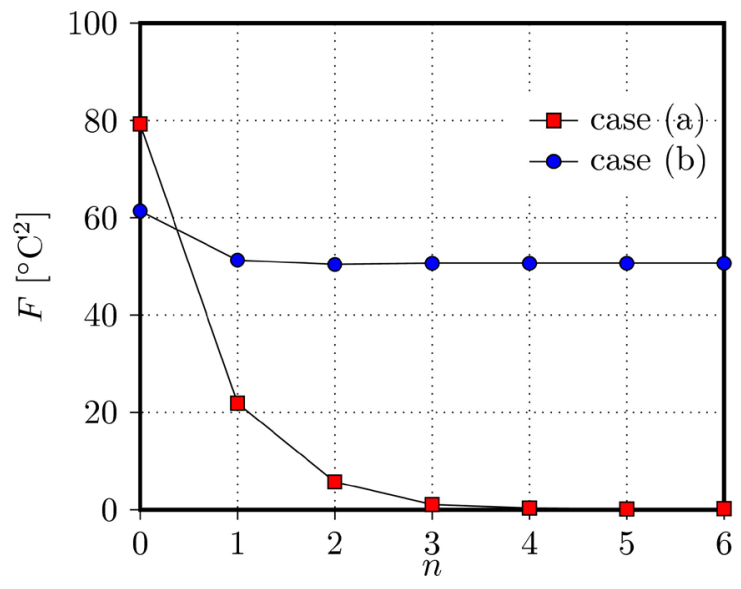

Figure 6. Objective Function.

the objective function is null, while case (b) stopped at certain values corresponding to a local minimum (Figure 7).

The result for case (b) may be due to the fact that, by taking as reference the temperature of the workpieces only, an excess on values of both parameters, i.e. the extent of the viscous dissipation and the heat transfer coefficient from the bottom of the workpiece, could result in an increase in heat generation, which could in return be compensated by an increase of the heat transfer to the backing plate. And so two higher values for both parameters do not converge to the global minimum.

In case (a) adding the temperature in the backing plate as reference, the parameters with excess value both operate increasing the heat transferred to the backing plate.

\section{Conclusions}

In this work, sensitivity analysis and parameter estimation for the identification of certain parameters involved in modeling the steady state of the friction stir welding process were presented.

The sensitivity analysis allowed to determine the way in which the parameters independently affect the temperature results. Three of them were found to be significant: $\eta$, the mechanical efficiency, $h_{b}$, the heat transfer coefficient of the workpieces-backing plate interface, and $\mu_{0}$, the friction constant. Parameters involved in the two sources of heat generation were found to be correlated.

The two cases considered to perform the estimation procedure showed the importance of the location of reference points -i.e. the temperature measurement locations when comparing the experimental data- in reaching the global minimum of the objective function. It has been recognized to be suitable to take reference points for the

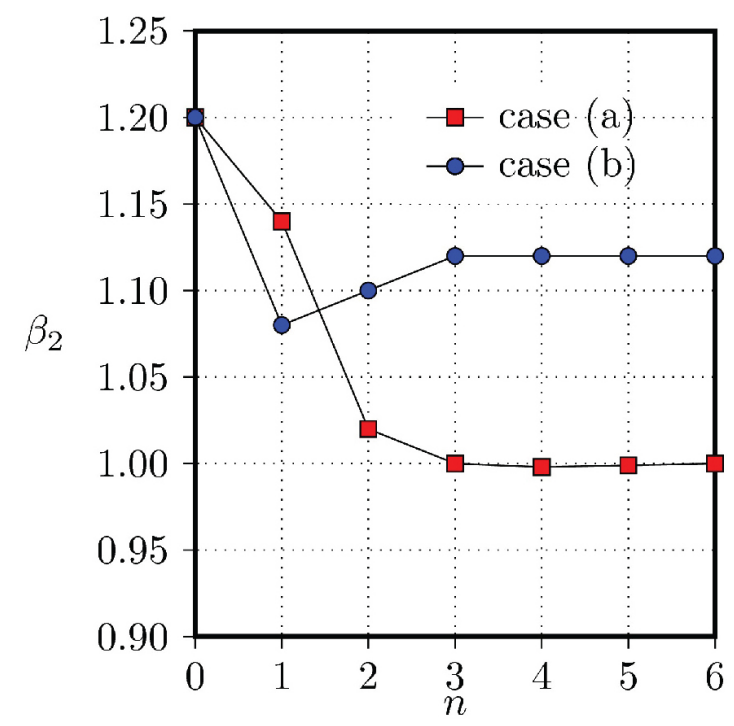

(a)

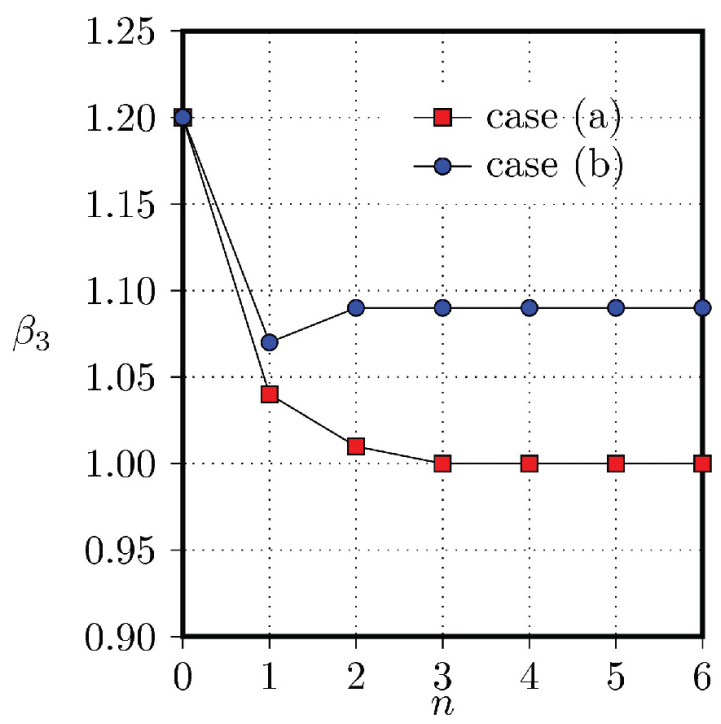

(b)

Figure 7. Normalized parameter (a) $\beta_{2}$ and (b) $\beta_{3}$.

temperature both in the workpieces and in the backing plate. However, reference temperatures in the backing plate are unusual in inverse analysis of FSW ${ }^{17,18,20,21}$.

In spite of the fact that the parameter involved in the fraction slip relationship $\left(\delta_{0}\right)$ do not significantly influence on the temperature field, it would affect the velocity field results adjacent to the tool. It could be estimated taking into account some geometrical magnitude of the stir zone, e.g. a characteristic length. 


\section{References}

1. Mishra RS and Ma ZY. Friction stir welding and processing. Materials Science and Engineering. 2005; 50:1-78. http:// dx.doi.org/10.1016/j.mser.2005.07.001

2. Nandan R, DebRoy T and Bhadeshia HKDH. Recent advances in friction-stir welding - Process, weldment structure and properties. Progress in Materials Science. 2008; 53(6):9801023. http://dx.doi.org/10.1016/j.pmatsci.2008.05.001

3. Ma ZY. Friction Stir Processing Technology: A Review. Metallurgical and Materials Transactions A. 2008; 39:642-658. http://dx.doi.org/10.1007/s11661-007-9459-0

4. Mariano DM No and Neto P. Numerical modeling of friction stir welding process: a literature review. International Journal of Advanced Manufacturing Technology. 2013; 65:115-126. http://dx.doi.org/10.1007/s00170-012-4154-8

5. Gould JE and Feng Z. Heat flow model for Friction Stir Welding of Aluminum Alloy. Journal of Material Processing \& Manufacturing Science. 1998; 7:185-194. http://dx.doi. org/10.1106/648R-2CNE-2PD0-45L6

6. Tang W, Guo X, McClure JC, Murr LE and Nunes A. Heat input and temperature distribution in Friction Stir Welding. Journal of Materials Processing \& Manufacturing Science. 1998; 2:163-172. http://dx.doi.org/10.1106/55TF-PF2GJBH2-1Q2B

7. Ulysse P. Three-dimensional modeling of the friction stirwelding process. International Journal of Machine Tools and Manufacture. 2002; 42(14):1549-1557. http://dx.doi. org/10.1016/S0890-6955(02)00114-1

8. Nandan R, Roy GG, Lienert TJ and Debroy T. Threedimensional heat and material flow during friction stir welding of mild steel. Acta Materialia. 2007; 55:883-895. http://dx.doi. org/10.1016/j.actamat.2006.09.009

9. Seidel TU and Reynolds AP. Two-dimensional friction stir welding process model based on fluid mechanics. Science and Technology of Welding and Joining. 2003; 8(3):175-183. http:// dx.doi.org/10.1179/136217103225010952

10. Soundararajan V, Zekovic S and Kovacevic R. ThermoMechanical Model with Adaptive Boundary Conditions for Friction Stir Welding of Al 6061. International Journal of Machine Tools and Manufacture. 2005; 45(14):1577-1587. http://dx.doi.org/10.1016/j.ijmachtools.2005.02.008

11. Schmidt HB and Hattel JH. Thermal Modelling in Friction Stir Welding. Scripta Materialia. 2008; 58(5):332-337. http:// dx.doi.org/10.1016/j.scriptamat.2007.10.008

12. Buffa G, Hua J, Shivpuri R and Fratini L. A continuum based fem model for friction stir welding-model development. Materials Science and Engineering: A. 2006; 419(1-2):389-396. http:// dx.doi.org/10.1016/j.msea.2005.09.040

13. Colegrove PA and Shercliff HR. 3-Dimensional CFD modelling of flow round a threaded friction stir welding tool profile. Journal of Materials Processing Technology. 2005; 169:320327. http://dx.doi.org/10.1016/j.jmatprotec.2005.03.015
14. Schmidt $\mathrm{H}$ and Hattel J. A local model for the thermomechanical conditions in friction stir welding. Modelling and Simulation in Materials Science and Engineering. 2005; 13:77-93. http:// dx.doi.org/10.1088/0965-0393/13/1/006

15. Grujicic M, He T, Arakere G, Yalavarthy HV, Yen C-F and Cheeseman BA. Fully coupled thermomechanical finite element analysis of material evolution during friction-stir welding of AA5083. Proceedings of The Institution of Mechanical Engineers Part B-journal of Engineering Manufacture. 2010; 224:609-625. http://dx.doi.org/10.1243/09544054JEM1750

16. De A and DebRoy T. A smart model to estimate effective thermal conductivity and viscosity in the weld pool. Journal of Applied Physics. 2004; 95(9):5230-5240. http://dx.doi. org/10.1063/1.1695593

17. Zhu XK and Chao YJ. Numerical simulation of transient temperature and residual stresses in friction stir welding of 304L stainless steel. Journal of Material Processing Technology. 2004; 146:263-272. http://dx.doi.org/10.1016/j. jmatprotec.2003.10.025

18. Nandan R, Prabu B, De A and Debroy T. Improving reliability of heat transfer and materials flow calculations during friction stir welding of dissimilar aluminum alloys. Welding Journal. 2007; 86:313-322.

19. Pereyra S, Lombera G, Urquiza S and De Vedia L. Modelado numérico del proceso de soldadura FSW incorporando una técnica de estimación de parámetros. In: Proceedings of The XXVIII Mecánica Computacional; 2009; Tandil. Tandil; 2009. p. 2745-2756.

20. Assidi M, Fourment L, Guerdoux S and Nelson T. Friction model for friction stir welding process simulation: Calibrations from welding experiments. International Journal of Machine Tools \& Manufacture. 2010; 50:143-155. http://dx.doi. org/10.1016/j.ijmachtools.2009.11.008

21. Larsen A, Stolpe M and Hattel JH. Estimating the workpiecebackingplate heat transfer coefficient in friction stir welding. Engineering Computations. 2012; 29(1):65-82. http://dx.doi. org/10.1108/02644401211190573

22. Urquiza SA and Venere MJ. An Application Framework architecture for FEM and other related solvers. In: Proceedings of The XXI Mecánica Computacional; 2002; Santa Fe-Paraná. Santa Fe-Paraná; 2002. p. 3099-3109.

23. SLATEC Common Mathematical Library. Version 1.4. 1993. Available from: <http://www.netlib.org/slatec/index.html>.

24. Sellars CM and Tegart WJM. La relation entre la résistance et la structure dans la deformation à chaud. Mémoires Scientifiques de la Revue de Metallurgie. 1966; 63:731-746.

25. Jorge AM Jr and Balancin O. Prediction of steel flow stresses under hot working conditions. Material Research. 2005;8:309-315.

26. Beck JV and Arnold KJ. Parameter Estimation in Engineering and Science. New York: Wiley \& Sons; 1977. 